\title{
Inhibitory effects of Hedyotis diffusa Willd. on colorectal cancer stem cells
}

\author{
GUODONG SUN ${ }^{1 *}$, LIHUI WEI $^{2,3 *}$, JIANYU FENG $^{2,3}$, JIUMAO LIN $^{2,3}$ and JUN PENG ${ }^{2,3}$ \\ ${ }^{1}$ Hangzhou Naval Sanatorium of Nanjing Military Area Command, Hangzhou, Zhejiang 310002; \\ ${ }^{2}$ Academy of Integrative Medicine; ${ }^{3}$ Fujian Key Laboratory of Integrative Medicine on Geriatrics, \\ Fujian University of Traditional Chinese Medicine, Fuzhou, Fujian 350122, P.R. China
}

Received August 3, 2015; Accepted February 25, 2016

DOI: $10.3892 / \mathrm{ol} .2016 .4431$

\begin{abstract}
Cancer stem cells (CSCs) are proposed to be closely correlated with the development and progression of tumors, as well as with chemo- and radioresistance. Targeting CSCs may therefore be a promising potential strategy for the treatment of cancer. Currently, natural products have received great interest due to their therapeutic efficacy and reduced adverse effects compared with modern chemotherapeutics. As a significant component of a number of traditional Chinese medicine formulas, the medicinal herb Hedyotis diffusa Willd. (HDW) has long been utilized in China to clinically treat a variety of malignancies, including colorectal cancer (CRC). Previously, the authors of the present study reported that HDW suppressed CRC growth through multiple mechanisms, including promoting apoptosis, and inhibiting cell proliferation and tumor angiogenesis. To additionally investigate its mode of action, the present study isolated a stem-like side population (SP) from colorectal cancer HT-29 cells to investigate the effect of ethanol extract of HDW on CSCs. It was observed that HDW was able to markedly downregulate the expression of CSC marker leucine-rich repeat-containing G-protein coupled receptor 5 and also significantly decrease the proportion of SP in HT-29 cells, in a dose-dependent manner. Furthermore, HDW treatment significantly and dose-dependently inhibited the viability and sphere formation, and induced cell morphological changes of isolated HT-29 SP cells. In addition,
\end{abstract}

Correspondence to: Dr Jiumao Lin or Professor Jun Peng, Academy of Integrative Medicine, Fujian University of Traditional Chinese Medicine, 1 Qiuyang Road, Fuzhou, Fujian 350122, P.R. China

E-mail: jiumaolin@hotmail.com

E-mail: pjunlab@hotmail.com

${ }^{*}$ Contributed equally

Abbreviations: CRC, colorectal cancer; HDW, Hedyotis diffusa Willd.; CSCs, cancer stem cells; SP, side population

Key words: Hedyotis diffusa Willd., traditional Chinese medicine, cancer stem cells, side population
HDW greatly suppressed the messenger RNA expression of several critical genes that mediate CSC features, including ATP-binding cassette, sub-family B, member $1, \beta$-catenin, c-Myc, proliferating cell nuclear antigen and survivin. In conclusion, the present study indicates that HDW may exert inhibitory effects on cancer stem cells.

\section{Introduction}

Due to changes in diet structure and lifestyle, as well as the increase in the aging population, colorectal cancer (CRC) has become one of the most commonly observed malignancies worldwide, accounting for $>1.2$ million new cases and $>600,000$ mortalities each year $(1,2)$. Although surgical resection provides the most positive prognosis for long-term survival, the majority of CRC patients are not suitable for surgery, as at the time of diagnosis they already present with metastatic disease $(3,4)$. Therefore, chemotherapy remains a major therapeutic approach for the treatment of patients exhibiting advanced CRC. Despite the progress that has been achieved in the field of chemotherapy, the long-term prognosis of CRC remains poor due to the development of drug resistance, severe adverse effects, metastasis and recurrence (4-6). It has been proposed that cancer may arise from a small population of cells known as cancer stem cells (CSCs) (7). CSCs demonstrate stem cell properties, including continuous self-renewal and multi-directional differentiation, as well as natural resistance to chemo- and radiotherapy, leading to the initiation, progression and relapse of cancer (8). Thus, targeting CSCs may be a promising strategy for anticancer treatment (9).

Currently, natural products have received great interest due to their therapeutic efficacy and reduced adverse effects compared with modern chemotherapeutics (10-12). Hedyotis diffusa Willd. (HDW), a member of the Rubiaceae family, is a well-known traditional Chinese medicinal herb that is widely distributed throughout northeast Asia. As a critical ingredient of several traditional Chinese medicine formulas, HDW has long been utilized in China to clinically treat various malignancies, including CRC. Previously, the authors of the present study demonstrated that HDW demonstrates a wide range of antitumor activities, by affecting multiple intracellular targets (13-16). To additionally elucidate the underlying mechanism of the tumoricidal activity of HDW, the present 
study isolated a stem-like side population (SP) from CRC HT-29 cells to investigate the effect of HDW on CSCs.

\section{Materials and methods}

Materials and reagents. Dulbecco's modified Eagle's medium (DMEM), DMEM/F12, fetal bovine serum (FBS), penicillin, streptomycin, $0.25 \%$ trypsin-ethylenediaminetetraacetic acid (EDTA), 50X B27 supplement, Pierce radioimmunoprecipitation assay Buffer, Pierce bicinchoninic acid (BCA) Protein assay kit, SuperSignal ${ }^{\mathrm{TM}}$ West Pico Chemiluminescent Substrate and DreamTaq Green PCR Master mix (2X) were all purchased from Thermo Fisher Scientific, Inc. (Waltham, MA, USA). Epidermal growth factor (EGF) and basic fibroblast growth factor (bFGF) were obtained from PeproTech (Rocky Hill, NJ, USA). Hoechst 33342 and verapamil were purchased from Sigma Chemicals (St. Louis, MO, USA). Leucine-rich repeat-containing G-protein coupled receptor 5 (Lgr5; catalog. no. ab75732) and glyceraldehyde-3-phosphate dehydrogenase (GAPDH; catalog. no. ab181602) rabbit polyclonal antibodies were purchased from Abcam (Cambridge, UK). Horseradish peroxidase (HRP)-conjugated goat anti-rabbit secondary antibody (catalog. no. E030120-01) was purchased from Earthox (Millbrae, CA, USA). RNAiso Plus reagent and PrimeScript ${ }^{\mathrm{TM}}$ Reverse Transcription (RT) Reagent kit were purchased from Takara Bio, Inc. (Dalian, Liaoning, China). Water-soluble tetrazolium salts (WST)-1 assay kit and Blocking buffer were purchased for Beyotime Institute of Biotechnology (Shanghai, China).

Preparation of ethanol extract of HDW (EEHDW). EEHDW was prepared as previously described (16). Stock solutions of EEHDW were prepared by dissolving the EEHDW powder in a concentration of $40 \%$ dimethyl sulfoxide (DMSO; catalog. no. 67-68-5; Amresco, Solon, OH, USA) to achieve a final concentration of $400 \mathrm{mg} / \mathrm{ml}$. Working concentrations of EEHDW were created by diluting the stock solution in culture medium (DMEM for HT-29 cells or DMEM/F12 for SP cells). The final concentration of DMSO in the culture medium was $<0.5 \%$.

HT-29 cell culture. Human CRC HT-29 cells were purchased from the Cell Bank of the Chinese Academy of Sciences (Shanghai, China). The cells were grown in DMEM containing $10 \%$ (v/v) FBS, $100 \mathrm{U} / \mathrm{ml}$ penicillin and $100 \mu \mathrm{g} / \mathrm{ml}$ streptomycin in a $37^{\circ} \mathrm{C}$ humidified incubator with an atmosphere of $5 \% \mathrm{CO}_{2}$.

Isolation and culture of SP. The SP assay is based on the efflux of Hoechst dye from cells via the ATP-binding cassette $(\mathrm{ABC})$ family of transporter proteins expressed within the cell membrane. In the two-dimensional flow analysis chart, the cells are located on the side of a main cell population in a comet-like distribution; these cells are termed the 'side population'. The verapamil control is an ABC transporter inhibitor. The SP from HT-29 cells was isolated and analyzed using MoFloTM XDP cell sorter flow cytometry (Beckman Coulter, Inc., Brea, CA, USA) as described previously (17). Briefly, the HT-29 cells were digested with $0.25 \%$ trypsin-EDTA and re-suspended in DMEM (supplemented with 2\% FBS) at a concentration of $2.5 \times 10^{6}$ cells $/ \mathrm{ml}$. Fresh Hoechst 33342 $\left(10 \mu \mathrm{g} / \mathrm{ml}\right.$ final concentration) was added for $30 \mathrm{~min}$ at $37^{\circ} \mathrm{C}$ in a rotary shaker. As a control, certain cells were incubated with Hoechst 33342 in the presence of $50 \mu \mathrm{M}$ verapamil. At the end of incubation, the cells were washed and re-suspended in cold phosphate-buffered saline (PBS), then $1 \mathrm{mg} / \mathrm{ml}$ propidium iodide was added, and the cells were kept at $4^{\circ} \mathrm{C}$ in the dark. Excitation of Hoechst dye was performed with an ultraviolet laser (catalog. no. CY-355-100; JDSU, Milpitas, CA, USA) at $355 \mathrm{~nm}$, and the fluorescence was measured using a $450 \pm 25 \mathrm{~nm}$ filter (Hoechst blue) and a $620 \pm 15-\mathrm{nm}$ filter (Hoechst red). Sorted SP cells were cultured in serum-free stem cell DMEM/F12 culture medium, containing B27 supplement (1X), $20 \mathrm{ng} / \mathrm{ml}$ EGF and $20 \mathrm{ng} / \mathrm{ml} \mathrm{bFGF}$.

Sphere formation assay. Isolated HT-29 SP cells were seeded at a density of $2 \times 10^{5}$ cells/well into 6-well plates (NEST Biotechnology Co., Ltd., Wuxi, Jiangsu, China) in $2 \mathrm{ml}$ DMEM culture medium. Following treatment with various concentrations of EEHDW $(0,0.5,1$ and $2 \mathrm{mg} / \mathrm{ml})$ for $24 \mathrm{~h}$ at $37^{\circ} \mathrm{C}$, cells were digested with $0.25 \%$ trypsin-EDTA and seeded at a density of $1.0 \times 10^{3}$ cells/well into Costar ${ }^{\circledR} 6$-well Ultra-Low attachment plates (Corning, Inc., Corning, NY, USA), and cultured in DMEM/F12 serum-free stem cell culture medium. The medium was replaced every 2 days. Following 15 days of incubation, cells were collected and transferred into a new well in a 96-well plate (catalog. no. 205512; BD Diagnostics, Sparks Glencoe, MD, USA); and images were captured using a BD Pathway ${ }^{\mathrm{TM}} 855$ at magnification, x100 (BD Biosciences, Franklin Lakes, NJ, USA). A spheroid with $>50$ cells inside was considered to be a full sphere.

Cell viability analysis. Cell viability was analyzed by WST-1 assay. Sorted SP cells were seeded at a density of $2.0 \times 10^{4}$ cells/well into 96 -well plates, and incubated with serum-free stem cell culture medium for a total of $48 \mathrm{~h}$ at $37^{\circ} \mathrm{C}$. Subsequently, cells were treated with various concentrations of EEHDW (0, 0.5, 1 and $2 \mathrm{mg} / \mathrm{ml})$ for $24 \mathrm{~h}$ at $37^{\circ} \mathrm{C}$. At the conclusion of the treatment period, $10 \mu \mathrm{l}$ WST-1 were added to each well, and the samples were incubated for an additional $2 \mathrm{~h}$ at $37^{\circ} \mathrm{C}$. The absorbance was measured at $450 \mathrm{~nm}$ using a microplate reader (ELx800 Absorbance Reader; BioTek Instruments, Inc., Winooski, VT, USA).

Observation of morphological changes. The sorted SP cells were seeded into 96 -well plates at a density of $2.0 \times 10^{4}$ cells/well in $0.1 \mathrm{ml}$ serum-free stem cell culture medium. The cells were treated with various concentrations of EEHDW ( 0 , $0.5,1$ and $2 \mathrm{mg} / \mathrm{ml}$ ) for $24 \mathrm{~h}$ at $37^{\circ} \mathrm{C}$. Cell morphology was observed using a phase-contrast microscope (DMIL/DFC295; Leica Microsystems GmbH, Wetzlar, Germany). Images were captured at x200 magnification.

Western blotting. HT-29 cells were seeded at a density of $2.5 \times 10^{5}$ cells/well into 6-well plates in $2 \mathrm{ml}$ DMEM medium, and were treated with various concentrations of EEHDW $(0$, $0.5,1$ and $2 \mathrm{mg} / \mathrm{ml}$ ) for a total of $24 \mathrm{~h}$ at $37^{\circ} \mathrm{C}$. The treated cells were washed with PBS and scraped off into a tube, then lysed using lysis buffer containing protease and phosphatase inhibitor cocktails on ice for $15 \mathrm{~min}$. Following high-speed 
Table I. Primer sequences for reverse transcription-polymerase chain reaction.

\begin{tabular}{ll}
\hline Gene & \multicolumn{1}{c}{ Primers, ' $\rightarrow 3 '^{\prime}$} \\
\hline ABCB1 & \\
Forward & TGACATTTATTCAAAGTTAAAAGCA \\
Reverse & TAGACACTTTATGCAAACATTTCAA \\
$\begin{array}{l}\text { s-catenin } \\
\text { Forward }\end{array}$ & CCCACTGGCCTCTGATAATGG \\
Reverse & ACGCAAAGGTGCATGATTTG \\
c-Myc & \\
Forward & CAGCTGCTTAGACGCTGGATT \\
Reverse & GTAGAAATACGGCTGCACCGA \\
PCNA & \\
Forward & CCAAACCAGGAGAAAGT \\
Reverse & GTGTCACCGTTGAAGAG \\
Survivin & \\
Forward & CAGATTTGAATCGCGGGACCC \\
Reverse & CCAAGTCTGGCTCGTTCTCAG \\
GAPDH & \\
Forward & CGACCACTTTGTCAAGCTCA \\
Reverse & AGGGGTCTACATGGCAACTG \\
\hline
\end{tabular}

ABCB1, ATP-binding cassette, sub-family B, member 1; PCNA, proliferating cell nuclear antigen; GAPDH, glyceraldehyde-3-phosphate dehydrogenase.

centrifugation $(12,000 \mathrm{x} \mathrm{g})$ for $20 \mathrm{~min}$ at $4^{\circ} \mathrm{C}$, supernatant containing the sample proteins was collected. The concentration of proteins was determined using the BCA Protein Assay Reagent kit. A total of $50 \mu \mathrm{g}$ of protein was resolved using $10 \%$ sodium dodecyl sulfate polyacrylamide gel electrophoresis and blotted onto nitrocellulose membranes. The membranes were blocked with blocking buffer and probed with primary antibodies against Lgr5 or GAPDH $(1: 1,000)$ overnight at $4^{\circ} \mathrm{C}$, and subsequently with the appropriate HRP-conjugated goat anti-rabbit secondary antibody $(1: 5,000)$ for $1 \mathrm{~h}$ at room temperature. The chemiluminescence signals were visualized using the SuperSignal ${ }^{\mathrm{TM}}$ West Pico Chemiluminescent Substrate. Image $\mathrm{Lab}^{\mathrm{TM}}$ Software, version 3.0, was used for densitometric analysis/quantification of the western blotting (Bio-Rad Laboratories Inc., Hercules, CA, USA).

$R T$-polymerase chain reaction $(R T-P C R)$ analysis. Total RNA from the HT-29 cells was isolated with RNAiso Plus reagent. Oligo (dT)-primed RNA (1 $\mu \mathrm{g})$ was reverse transcribed using the PrimeScript RT Reagent kit according to the manufacturer's protocol. Briefly, the gDNA Eraser $(1 \mu \mathrm{l})$ contained in the kit was used to remove the genomic DNA following incubation with the total RNA for $2 \mathrm{~min}$ at $42^{\circ} \mathrm{C}$, then the PrimeScript RT Enzyme mix and RT Primer mix were added to perform RT using incubation for $15 \mathrm{~min}$ at $37^{\circ} \mathrm{C}$. The obtained complementary DNA was used to determine the messenger (m)RNA quantity of c-Myc, $\beta$-catenin, PCNA, survivin and ABCB1 by PCR, using the DreamTaq Green PCR Master mix (2X).
PCR was performed by the 3-step method, with a denaturation stage at $95^{\circ} \mathrm{C}$ for $30 \mathrm{sec}$, an annealing stage at an appropriate temperature $\left(55^{\circ} \mathrm{C}\right.$ for $\mathrm{c}-\mathrm{Myc}, \beta$-catenin and survivin, and $58^{\circ} \mathrm{C}$ for PCNA, ABCB1 and GAPDH) for $30 \mathrm{sec}$ and an extension stage at $60^{\circ} \mathrm{C}$ for $30 \mathrm{sec}$ for 30 cycles. GAPDH was used as an internal control. The primer were synthesized by Invitrogen, Thermo Fisher Scientific Inc., (Waltham, MA, USA) and the sequences used in the RT-PCR are listed in Table I. A negative control with no DNA and an RT control with no reverse transcription were used as the experimental controls. The PCR was repeated in three independent experiements. A Bio-Rad S1000 Thermal Cycler was used to perform the experiment, and Image Lab ${ }^{\mathrm{TM}}$ Software, version 3.0, was used for quantification/densitometric analysis (both Bio-Rad Laboratories Inc.).

Statistical analysis. Data were analyzed using SPSS for Windows (version 17.0; SPSS, Inc. Chicago, IL, USA). Statistical analysis of the data was performed with Student's t-test and analysis of variance. $\mathrm{P}<0.05$ was considered to indicate a statistically significant difference.

\section{Results}

EEHDW reduces the SP proportion in HT-29 cells. The effect of EEHDW on cancer stem cells was determined by examining the SP proportion in HT-29 cells. As demonstrated in Fig. 1, similar to verapamil, a multi-drug transporter inhibitor that is typically used as a positive control in SP analysis, EEHDW significantly reduced the percentage of SP in HT-29 cells in a dose-dependent manner compared with the control $(\mathrm{P}<0.05)$. In order to confirm these results, the expression of Lgr5, which is considered to be a bio-marker of CSCs, was detected. As shown in Fig. 2, EEHDW significantly and dose-dependently downregulated Lgr5 protein expression compared with the control $(\mathrm{P}<0.05)$.

EEHDW inhibits the sphere formation capacity and viability of isolated HT-29 SP cells. In order to investigate EEHDW's effect on CSC growth, the present study evaluated the sphere formation of isolated HT-29 SP cells. As shown in Fig. 3A and B, EEHDW dose-dependently suppressed SP sphere formation compared with the control $(\mathrm{P}<0.05)$. In order to verify the growth-suppressive activity of EEHDW in CSCs, the viability of isolated HT-29 SP cells was determined. As demonstrated in Fig. 3C, EEHDW treatment significantly reduced SP viability in a dose-dependent manner compared with the control $(\mathrm{P}<0.05)$. The growth inhibition ability of EEHDW was confirmed by its effect on SP cell morphology via phase-contrast microscopy, as cell morphology in culture is indicative of the healthy status of the cells. As shown in Fig. 4, following incubation with various concentrations of EEHDW (0, 0.5, 1 and $2 \mathrm{mg} / \mathrm{ml})$ for $24 \mathrm{~h}$ the majority of the cells became shrunken and less confluent. Taken together, these data demonstrate that EEHDW inhibits the growth of isolated HT-29 SP cells.

EEHDW suppresses the expression of $A B C B 1, \beta$-catenin $c-M y c, P C N A$ and survivin in isolated HT-29 SP cells. In order to elucidate the underlying mechanism of the anti-CSC 
A

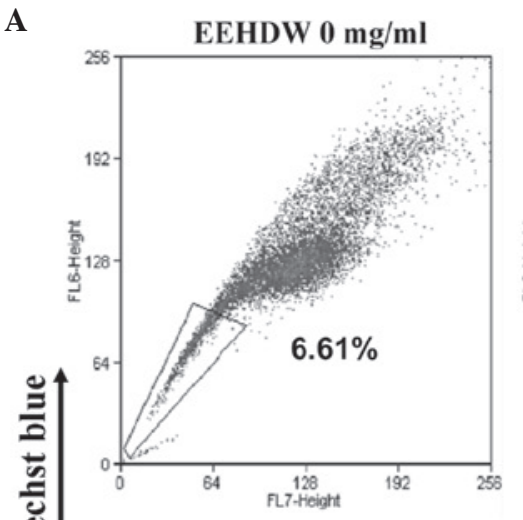

EEHDW $0.5 \mathrm{mg} / \mathrm{ml}$

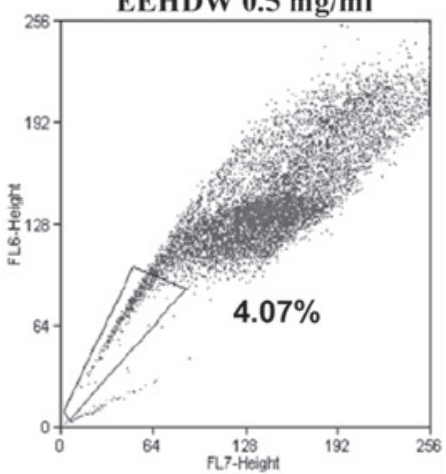

EEHDW $1 \mathrm{mg} / \mathrm{ml}$

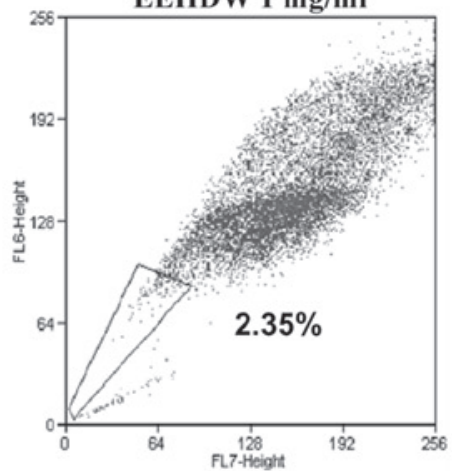

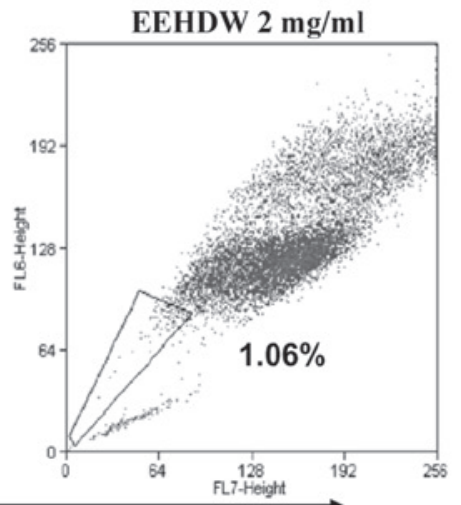

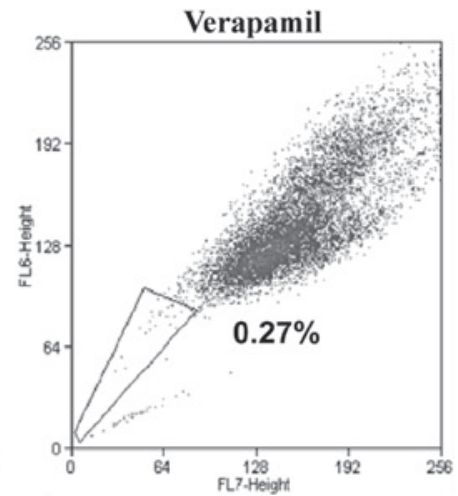

Hoechst red

B

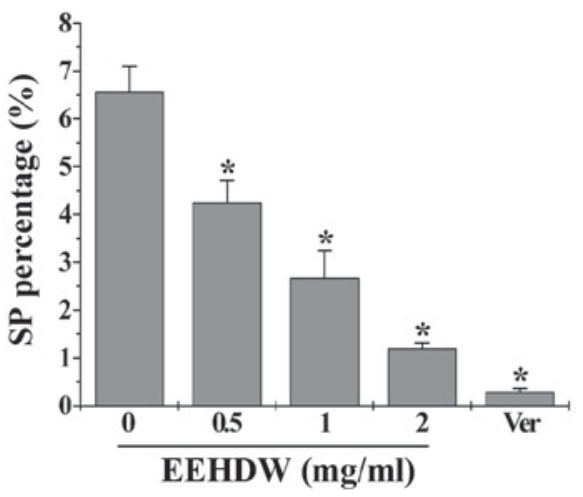

Figure 1. EEHDW inhibits the percentage of SP in human colorectal cancer HT-29 cells. (A) Following treatment with various concentrations of EEHDW (0, $0.5,1$ and $2 \mathrm{mg} / \mathrm{ml}$ ) for $24 \mathrm{~h}, \mathrm{HT}-29$ cells were stained with Hoechst 33342 and percentages of SP were analyzed by FACS. Verapamil was used as a positive control. (B) Quantification of FACS analysis. Images are representative and data are expressed as the mean \pm standard deviation of 3 independent experiments. ${ }^{*} \mathrm{P}<0.05$ vs. untreated control cells. EEHDW, ethanol extract of Hedyotis diffusa Willd.; SP, side population; FACS, fluorescence-activated cell sorting.

A

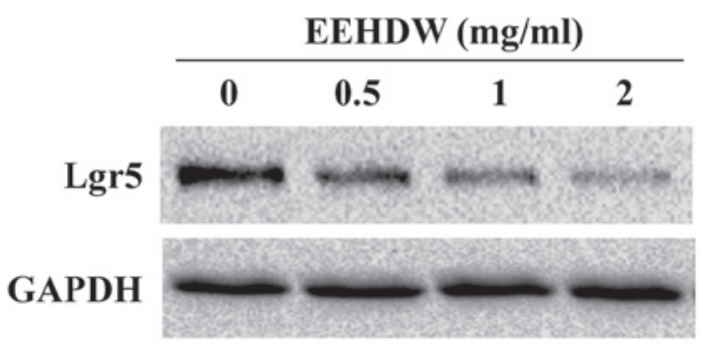

B

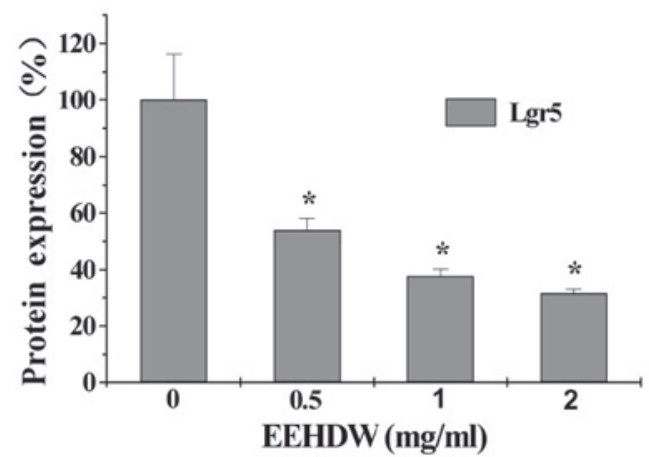

Figure 2. EEHDW inhibits the protein expression of Lgr5 in HT-29 cells. (A) The protein expression of Lgr5 in HT-29 cells was determined by western blot analysis. GAPDH was used as the internal control. (B) Densitometric analysis. The data were normalized to the mean protein expression of untreated control cells $(100 \%)$. Images are representative and data are presented as the mean \pm standard deviation of 3 independent experiments. ${ }^{*} \mathrm{P}<0.05$ vs. untreated control cells. EEHDW, ethanol extract of Hedyotis diffusa Willd.; Lgr5, Leucine-rich repeat-containing G-protein coupled receptor 5; GAPDH, glyceraldehyde-3-phosphate dehydrogenase. 


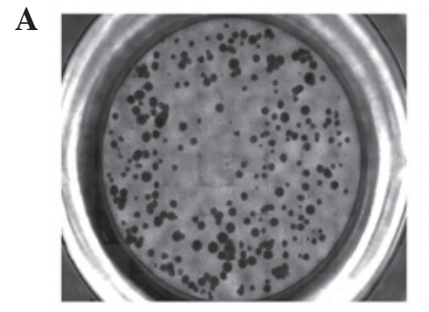

EEHDW $0 \mathrm{mg} / \mathrm{ml}$

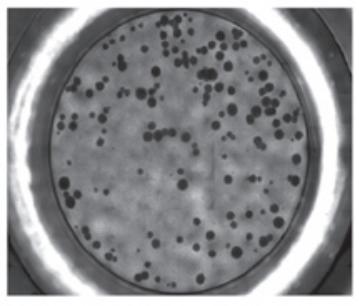

EEHDW $0.5 \mathrm{mg} / \mathrm{ml}$

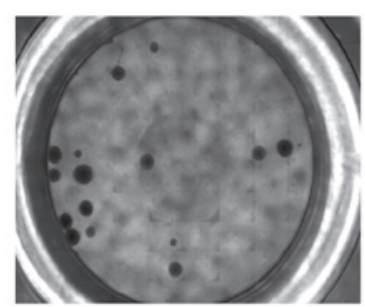

EEHDW $1 \mathrm{mg} / \mathrm{ml}$

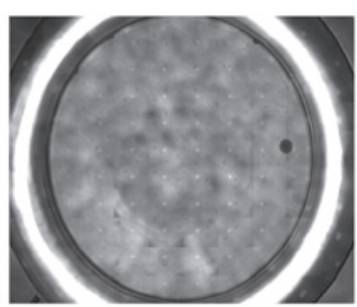

EEHDW $2 \mathrm{mg} / \mathrm{ml}$

B

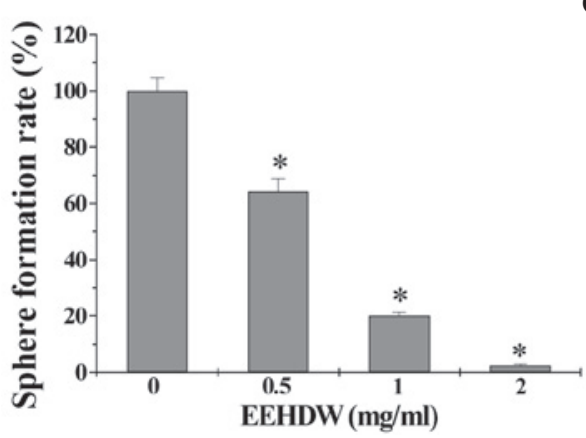

C

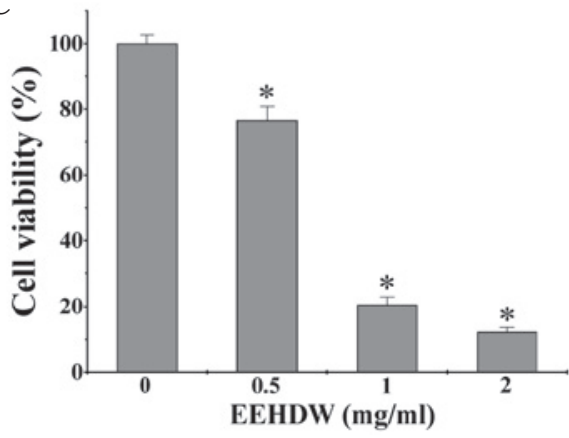

Figure 3. EEHDW inhibits the sphere formation capacity and viability of isolated HT-29 SP cells. (A) Following treatment with various concentrations $(0,0.5$, 1 and $2 \mathrm{mg} / \mathrm{ml}$ ) of EEHDW, SP cells were grown in serum-free stem cell culture medium for 15 days. Spheroids ( $>50$ cells) were counted and photographed. (B) Quantification of sphere formation analysis. Images are representative and data are presented as the mean \pm standard deviation of 3 independent experiments. "P $<0.05$ vs. untreated control cells. (C) SP cells were treated with the indicated concentrations $(0,0.5,1 \mathrm{and} 2 \mathrm{mg} / \mathrm{ml})$ of EEHDW for $24 \mathrm{~h}$. Cell viability was determined by the water-soluble tetrazolium salts- 1 assay. Data are presented as the mean \pm standard deviation. ${ }^{*} \mathrm{P}<0.05$ vs. untreated control cells. EEHDW, ethanol extract of Hedyotis diffusa Willd.; SP, side population.
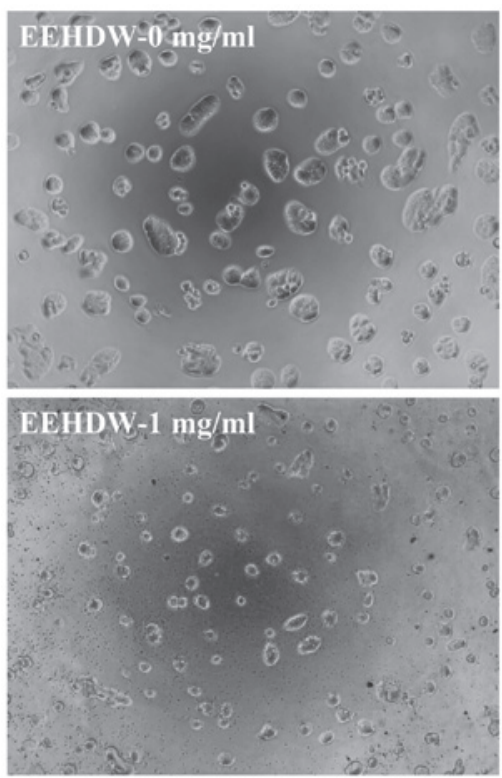
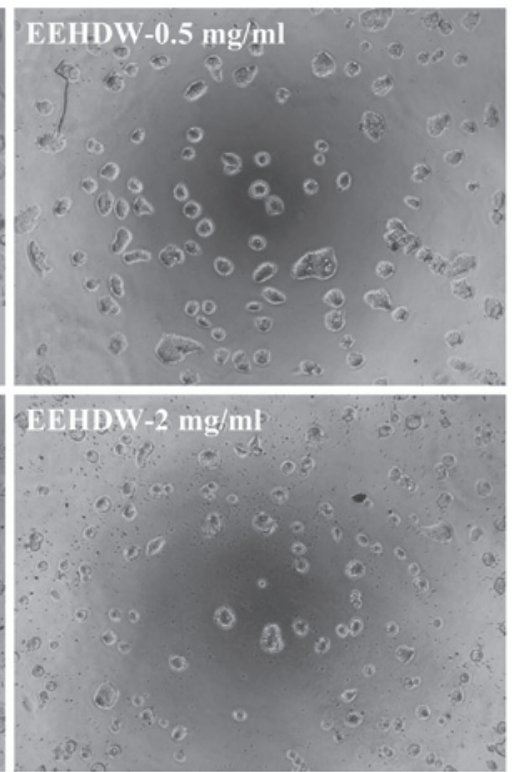

Figure 4. EEHDW induces morphological changes in isolated HT-29 SP cells. Sorted SP cells were treated with the indicated concentrations $(0,0.5,1$ and $2 \mathrm{mg} / \mathrm{ml}$ ) of EEHDW for $24 \mathrm{~h}$ and morphological changes were observed using phase-contrast microscopy. The images were captured at magnification, $\mathrm{x} 200$. Images are representative of 3 independent experiments. EEHDW, ethanol extract of Hedyotis diffusa Willd.; SP, side population. 
A

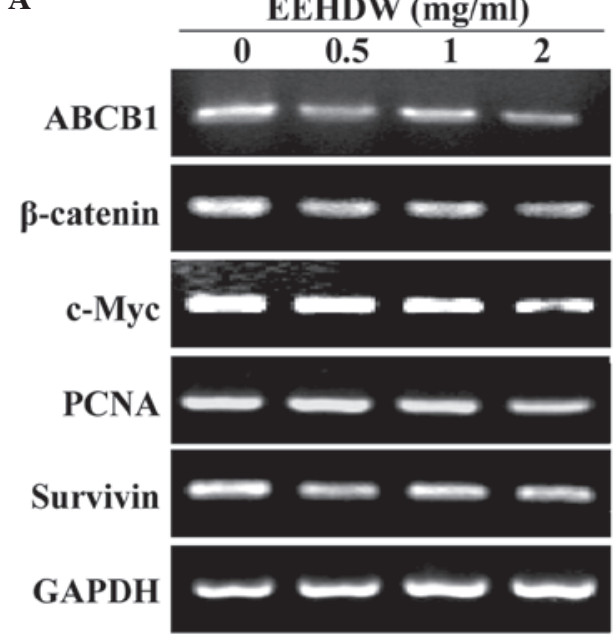

B

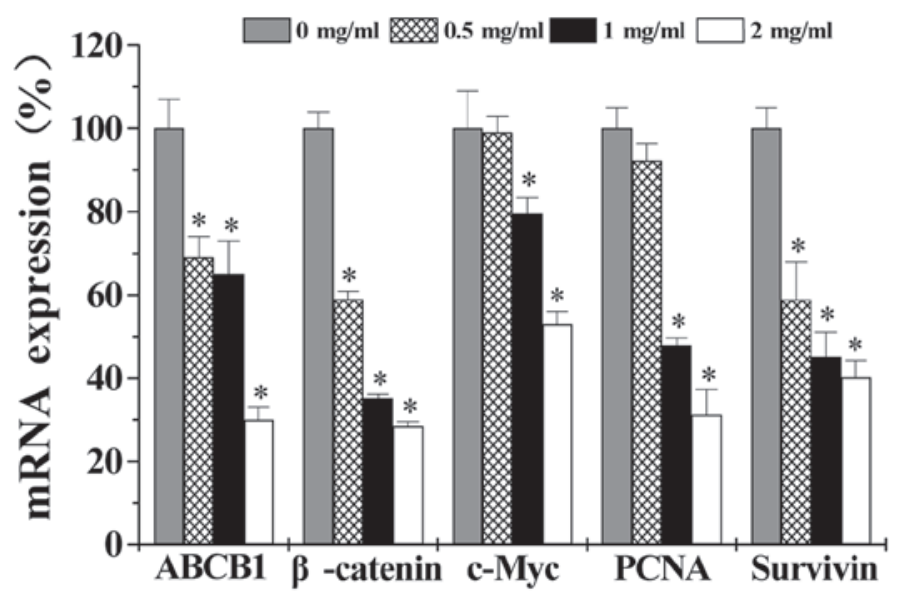

Figure 5. EEHDW suppresses the mRNA expression of ABCB1, $\beta$-catenin, c-Myc, PCNA and survivin in isolated HT-29 SP cells. (A) Following treatment with the indicated concentrations $(0,0.5,1$ and $2 \mathrm{mg} / \mathrm{ml})$ of EEHDW for $24 \mathrm{~h}$, the mRNA expression of ABCB1, $\beta$-catenin, c-Myc, PCNA and survivin in sorted HT-29 SP cells was determined by reverse transcription-polymerase chain reaction. GAPDH was used as the internal control. (B) Densitometric analysis. The data were normalized to the mean mRNA expression of untreated controls $(100 \%)$. Images are representative and data are presented as the mean \pm standard deviation of 3 independent experiments. " $<<0.05$ vs. untreated control cells. EEHDW, ethanol extract of Hedyotis diffusa Willd.; mRNA, messenger RNA; ABCB1, ATP-binding cassette, sub-family B, member 1; PCNA, proliferating cell nuclear antigen; SP, side population; GAPDH, glyceraldehyde-3-phosphate dehydrogenase.

activity of EEHDW, the present study examined the expression of ABCB1, $\beta$-catenin, c-Myc, PCNA and survivin in isolated HT-29 SP cells. As demonstrated in Fig. 5, EEHDW treatment markedly reduced the mRNA levels of the aforementioned genes in the SP cells compared with the control $(\mathrm{P}<0.05)$.

\section{Discussion}

Accumulating evidence has revealed the existence of cancer stem cells (CSCs) in the majority of leukemias and a number of solid tumors, including colorectal cancer (18-21). Their stem cell-like characteristics give CSCs the capacity for continuous self-renewal, multi-directional differentiation and natural drug resistance, resulting in cancer relapse and metastasis, and leading to the eventual failure of clinical anticancer treatment $(8,9)$. Therefore, discovering novel agents that target CSCs has the potential to improve the effectiveness of anticancer treatment. Natural products, including traditional Chinese medicines, have gained great attention as certain naturally-occurring compounds have been demonstrated to possess anti-CSC activity (17,22). HDW is a well-known medicinal herb that is utilized in traditional Chinese medicine formulas as an alternative treatment for various types of cancer. Previous studies have proposed that HDW may possess a wide range of anticancer activities by affecting multiple intracellular targets (13-16), suggesting that it may be a novel and potent therapeutic agent for the treatment of cancer. However, to the best of our knowledge, the effect of HDW on CSCs has never previously been studied.

Side population (SP) analysis is a commonly utilized technique for the identification and isolation of CSCs, and is based on the ability of CSCs to efflux Hoechst dye, due to the overexpression of ABC transporter proteins (23-26). SP cells have been identified in various types of cancer and have been observed to be correlated with tumor grade and patient prognosis (27-30). In the present study, the stem-like cells were isolated from the colon cancer cell line HT-29 as SP using fluorescence-activated cell sorting. It was observed that HDW was able to reduce the percentage of SP in HT-29 cells, and inhibit the viability, sphere formation and cell growth of isolated SP cells, indicating that HDW may be a useful agent for suppressing the growth of cancer stem cells.

ABC transporter proteins are part of the superfamily of membrane pumps that remove certain xenobiotics from cells, including chemotherapeutic drugs and lipophilic fluorescent dyes, and contribute to the SP phenotype and chemotherapy resistance. $\mathrm{ABC}$ transporters are frequently overexpressed in CSCs (23-26). In addition, the differentiation and self-renewal of CSCs is regulated strictly by multiple signal transduction pathways, including Wnt signaling (31). The activity of this signaling pathway is typically determined by the amount of stabilized $\beta$-catenin in the cytoplasm. When $\beta$-catenin accumulates in the cytosol, it will translocate into the nucleus where it is able to interact with Tcf/Lcf transcription factors to regulate the transcription of target genes that mediate cell apoptosis and/or proliferation, including c-Myc, PCNA and survivin, which gives CSCs a survival advantage. It has been demonstrated that $\beta$-catenin is important in the maintenance of the CSC phenotype (32-34). In order to investigate the underlying mechanism whereby HDW was able to inhibit the growth of colorectal cancer stem-like cells, the present study examined the mRNA expression of ABCB1, $\beta$-catenin, c-Myc, PCNA and survivin. It was observed that HDW treatment markedly reduced the mRNA levels of the above-mentioned genes in isolated HT-29 SP cells, suggesting that HDW may suppress CSCs in HT-29 cells, potentially via inhibition of the expression of $\mathrm{ABC}$ transporters and the Wnt signaling pathway.

The present study reported that HDW was able to markedly downregulate the expression of the CSC marker, Lgr5, and also significantly decrease the proportion of stem-like SP colorectal cancer HT-29 cells. In addition, HDW treatment 
significantly inhibited the viability and sphere formation, and induced morphological changes in the isolated HT-29 SP cells. Furthermore, HDW greatly suppressed the expression of several critical genes that mediate CSC features. The findings in this study suggest that HDW may exert inhibitory effects on CSCs.

\section{Acknowledgements}

The present study was sponsored by the Research Fund for the Doctoral Program of Higher Education of China (Beijing, China; grant no. 20133519110003) and the Developmental Fund of Chen Keji Integrative Medicine (Fujian, China; grant nos. CKJ2014013 and CKJ2015007).

\section{References}

1. Siegel R, Desantis C and Jemal A: Colorectal cancer statistics, 2014. CA Cancer J Clin 64: 104-117, 2014.

2. Jemal A, Bray F, Center MM, Ferlay J, Ward E and Forman D: Global cancer statistics. CA Cancer J Clin 61: 69-90, 2011.

3. Markowitz SD and Bertagnolli MM: Molecular origins of cancer: Molecular basis of colorectal cancer. N Engl J Med 361: 2449-2460, 2009.

4. Montagnani F, Chiriatti A, Turrisi G, Francini G and Fiorentini G: A systematic review of FOLFOXIRI chemotherapy for the first-line treatment of metastatic colorectal cancer: Improved efficacy at the cost of increased toxicity. Colorectal Dis 13: 846-852, 2011

5. Lippman SM: The dilemma and promise of cancer chemoprevention. Nat Clin Pract Oncol 3: 523, 2006.

6. Longley DB, Allen WL and Johnston PG: Drug resistance, predictive markers and pharmacogenomics in colorectal cancer. Biochim Biophys Acta 1766: 184-196, 2006.

7. Alison MR, Lin WR, Lim SM and Nicholson LJ: Cancer stem cells: In the line of fire. Cancer Treat Rev 38: 589-598, 2012.

8. Dean M, Fojo T and Bates S: Tumour stem cells and drug resistance. Nat Rev Cancer 5: 275-284, 2005.

9. Zhou BB, Zhang H, Damelin M, Geles KG, Grindley JC and Dirks PB: Tumour-initiating cells: Challenges and opportunities for anticancer drug discovery. Nat Rev Drug Discov 8: 806-823, 2009.

10. Gordaliza M: Natural products as leads to anticancer drugs. Clin Transl Oncol 9: 767-776, 2007.

11. Lin JM, Wei LH, Chen YQ, Liu XX, Hong ZF, Sferra TJ and Peng J: Pien Tze Huang induced apoptosis in human colon cancer HT-29 cells is associated with regulation of the Bcl-2 family and activation of caspase 3. Chin J Integr Med 17: 685-690, 2011.

12. Shen AL, Hong F, Liu LY, Lin JM, Zhuang QC, Hong ZF and Peng J: Effects of Pien Tze Huang on angiogenesis in vivo and in vitro. Chin J Integr Med 18: 431-436, 2012.

13. Lin J, Chen Y, Wei L, Shen A, Sferra TJ, Hong Z and Peng J: Ursolic acid promotes colorectal cancer cell apoptosis and inhibits cell proliferation via modulation of multiple signaling pathways. Int J Oncol 43: 1235-1243, 2013.

14. Lin J, Wei L, Shen A, Cai Q, Xu W, Li H, Zhan Y, Hong Z and Peng J: Hedyotis diffusa Willd extract suppresses Sonic hedgehog signaling leading to the inhibition of colorectal cancer angiogenesis. Int J Oncol 42: 651-656, 2013.
15. Cai Q, Lin J, Wei L, Zhang L, Wang L, Zhan Y, Zeng J, Xu W, Shen A, Hong Z and Peng J: Hedyotis diffusa Willd inhibits colorectal cancer growth in vivo via inhibition of STAT3 signaling pathway. Int J Mol Sci 13: 6117-6128, 2012.

16. Lin J, Chen Y, Wei L, Chen X, Xu W, Hong Z, Sferra TJ and Peng J: Hedyotis diffusa Willd extract induces apoptosis via activation of the mitochondrion-dependent pathway in human colon carcinoma cells. Int J Oncol 37: 1331-1338, 2010.

17. Wei L, Chen P, Chen Y, Shen A, Chen H, Lin W, Hong Z, Sferra TJ and Peng J: Pien Tze Huang suppresses the stem-like side population in colorectal cancer cells. Mol Med Rep 9: 261-266, 2014.

18. Lapidot T, Sirard C, Vormoor J, Murdoch B, Hoang T, Caceres-Cortes J, Minden M, Paterson B, Caligiuri MA and Dick JE: A cell initiating human acute myeloid leukaemia after transplantation into SCID mice. Nature 367: 645-648, 1994.

19. Al-Hajj M, Wicha MS, Benito-Hernandez A, Morrison SJ and Clarke MF: Prospective identification of tumorigenic breast cancer cells. Proc Natl Acad Sci USA 100: 3983-3988, 2003.

20. O'Brien CA, Pollett A, Gallinger S and Dick JE: A human colon cancer cell capable of initiating tumour growth in immunodeficient mice. Nature 445: 106-110, 2007.

21. Ricci-Vitiani L, Lombardi DG, Pilozzi E, Biffoni M, Todaro M, Peschle C and De Maria R: Identification and expansion of human colon-cancer-initiating cells. Nature 445: 111-115, 2007.

22. Efferth T: Stem cells, cancer stem-like cells, and natural products. Planta Med 78: 935-942, 2012.

23. Golebiewska A, Brons NH, Bjerkvig R and Niclou SP: Critical appraisal of the side population assay in stem cell and cancer stem cell research. Cell Stem Cell 8: 136-147, 2011.

24. Zhou S, Schuetz JD, Bunting KD, Colapietro AM, Sampath J, Morris JJ, Lagutina I, Grosveld GC, Osawa M, Nakauchi H and Sorrentino BP: The ABC transporter Bcrp1/ABCG2 is expressed in a wide variety of stem cells and is a molecular determinant of the side-population phenotype. Nat Med 7: 1028-1034, 2001.

25. Robey RW, To KK, Polgar O, Dohse M, Fetsch P, Dean M and Bates SE: ABCG2: A perspective. Adv Drug Deliv Rev 61: 3-13, 2009.

26. Patrawala L, Calhoun T, Schneider-Broussard R,Zhou J, Claypool K and Tang DG: Side population is enriched in tumorigenic, stem-like cancer cells, whereas ABCG2+ and ABCG2- cancer cells are similarly tumorigenic. Cancer Res 65: 6207-6219, 2005.

27. Bleau AM, Hambardzumyan D, Ozawa T, Fomchenko EI, Huse JT, Brennan CW and Holland EC: PTEN/PI3K/Akt pathway regulates the side population phenotype and ABCG2 activity in glioma tumor stem-like cells. Cell Stem Cell 4: 226-235, 2009.

28. Chiba T, Kita K, Zheng YW, Yokosuka O, Saisho H, Iwama A, Nakauchi $\mathrm{H}$ and Taniguchi $\mathrm{H}$ : Side population purified from hepatocellular carcinoma cells harbors cancer stem cell-like properties. Hepatology 44: 240-251, 2006.

29. Haraguchi N, Utsunomiya T, Inoue H, Tanaka F, Mimori K, Barnard GF and Mori M: Characterization of a side population of cancer cells from human gastrointestinal system. Stem Cells 24: 506-513, 2006

30. Ho MM, Ng AV, Lam S and Hung JY: Side population in human lung cancer cell lines and tumors is enriched with stem-like cancer cells. Cancer Res 67: 4827-4833, 2007.

31. Takebe N, Harris PJ, Warren RQ and Ivy SP: Targeting cancer stem cells by inhibiting Wnt, Notch, and Hedgehog pathways. Nat Rev Clin Oncol 8: 97-106, 2011.

32. Klaus A and Birchmeier W: Wnt signaling and its impact on development and cancer. Nat Rev Cancer 8: 387-398, 2008.

33. Komiya Y and Habas R: Wnt signal transduction pathways. Organogenesis 4: 68-75, 2008.

34. Rao TP and Kühl M: An updated overview on Wnt signaling pathways: A prelude for more. Circ Res 106: 1798-1806, 2010. 